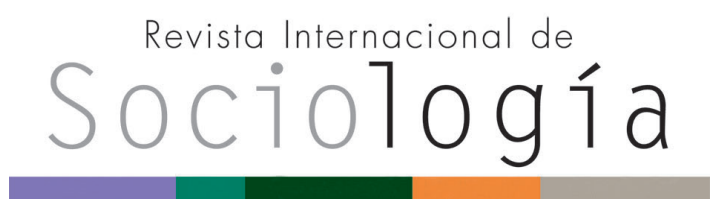

Revista Internacional de Sociología RIS

vol. 75 (2), e057, abril-junio, 2017, ISSN-L:0034-9712

doi: http://dx.doi.org/10.3989/ris.2017.75.2.15.58

\title{
COSMOPOLITISMO Y POLÍTICA DE LA TRADUCCIÓN
}

\section{COSMOPOLITANISM AND THE POLITICS OF TRANSLATION}

\author{
ESPERANZA Bielsa \\ Universidad Autónoma de Barcelona. España. \\ Esperanza.Bielsa@uab.cat \\ ORCID iD: http://orcid.org/0000-0001-5882-3382 \\ Antonio Aguilera \\ Universidad de Barcelona. España. \\ antaguilera@ub.edu \\ ORCID iD: http://orcid.org/0000-0001-9998-9338
}

Cómo citar este artículo / Citation: Bielsa, E. y A. Aguilera. 2017. "Cosmopolitismo y política de la traducción". Revista Internacional de Sociología 75 (2): e057. doi: http://dx.doi. org/10.3989/ris.2017.75.2.15.58
Copyright: (C) 2017 CSIC. Este es un artículo de acceso abierto distribuido bajo los términos de la licencia Creative Commons Attribution (CC BY) España 3.0.

Recibido: 10/04/2015. Aceptado: 11/03/2016. Publicado online: $24 / 05 / 2017$

\section{Abstract}

Translation has gained a central importance in recent accounts of cosmopolitanism which emphasise global interdependence and the interaction between different cultures and traditions. In this context, it becomes necessary to formulate a politics of translation that ques-tions some idealist assumptions about translation that are present in the sociological literature, specifies trans-lation as a fundamentally ethnocentric act, and formu-lates relevant strategies to confront this inherent ethno-centrism in order to open up translation to the difference of the other. Such politics consists in an extension of an ethics of translation based on linguistic hospitality, so that cultural asymmetries, inequalities and conflicts at a wider social level are addressed and political and normative responses to them can be devised from a cosmopolitan perspective. In this light, the relevance of a politics of translation as an alternative to a politics of identity is approached.

\section{KEYWORDS}

Cosmopolitanism; Ethnocentrism; Linguistic Hospitality; Translation.
Cosmopolitismo; Etnocentrismo; Hospitalidad lingüística; Traducción. 
1. La traducción aparece cada vez más como un proceso central de la comunicación intercultural en un contexto cosmopolita. Sin embargo, hasta hace poco su importancia había pasado en gran parte desapercibida en las ciencias sociales. La muestra más clara de ello podemos encontrarla en los estudios sobre la globalización, que han dedicado una mayor atención a la circulación de la información, de las ideas, de los bienes y de las personas que a las condiciones productivas que la hacen posible. Esto ha conducido a suponer que los públicos reciben automáticamente los textos que circulan a nivel global y a ocultar la intervención crucial de la traducción en la producción de múltiples versiones locales. De manera más general, frente a una teoría de la globalización que destaca la pretendida unicidad del mundo (el término que Roland Robertson empleó en 1992), la teoría social del cosmopolitismo subraya la multiplicidad de perspectivas, así como la interacción entre tradiciones diversas (Rumford 2008: 1). Al mismo tiempo, y en parte como resultado de este marcado cambio de orientación, la atención hacia la difusión homogeneizadora de un inglés simplificado -una lingua franca global que se percibía como el "McLanguage" de un "McWorld" globalizado o como el "Eurospeak" de nuestro continente multilingüe, (Snell-Hornby 2000: 17) - ha dado paso a una nueva percepción de la relevancia cultural y política del multilingüismo y de sus complejidades. Es en este contexto en el que destacados teóricos de lo que se ha denominado el nuevo cosmopolitismo advierten el papel mediador central que tiene la traducción entre modernidades o tradiciones distintas marcadas por la necesidad de relacionarse en un presente y futuro que es forzosamente intercultural. Así, para Ulrich Beck (2005: 126) la capacidad cosmopolita obliga a practicar el arte de traducir y tender puentes, relativizando la propia forma de vida en el horizonte de otras posibilidades; mientras que Gerard Delanty mantiene que los procesos cosmopolitas adoptan la forma de traducciones entre cosas distintas (2006: 43) y usa la noción de traducción cultural para destacar cómo una cultura se interpreta a sí misma a la luz del encuentro con el otro y experimenta importantes cambios como resultado de ello (2009: 19398). Aparece también una creciente consciencia de la importancia del multilingüismo y la traducción en aspectos clave del proyecto cosmopolita tales como la democracia global (Archibugi 2008), los derechos humanos (Benhabib 2002 y 2011; Santos 2010), la ciudadanía transnacional o cosmopolita (Benhabib 2004; Balibar 2006), los movimientos sociales (Santos 2005) y las fronteras (Balibar 2010). Para aproximarnos a la cuestión epistemológica que subyace a todas estas propuestas, podríamos decir que el planteamiento de Boaventura de Sousa Santos (2010), que propone una ecología de saberes y la traducción intercultural como alternativa a una teo- ría general que no puede comprender la infinita diversidad del mundo, demanda y hace imperativa la formulación de una política de la traducción.

2. Si el primer punto de este artículo se refiere a la constatación de que la traducción es un proceso clave de la comunicación intercultural en un contexto cosmopolita, un segundo paso es cuestionar nuestra definición más corriente de la traducción como transferencia de un mensaje verbal de una lengua a otra y revelar su radical insuficiencia para formular una política de la traducción. En este sentido, Etienne Balibar ha advertido una extraña reducción de lo que se entiende por traducción en nuestras constituciones políticas, defendiendo una concepción más amplia de la traducción como el instrumento básico que permite la creación de un espacio público transnacional en un sentido democrático en el que los ciudadanos puedan debatir ideas y proyectos más allá de las fronteras lingüísticas y administrativas (2006: 5-6). Para Balibar, la importancia política de la práctica de la traducción reside no en la transmisión de contenidos sino en la producción de un espacio de traducción, un "régimen de traducciones multilateral y multicultural". La traducción es concebida como el idioma "común" de esta nueva esfera pública, representando una forma de universalismo práctico, en oposición a la idea del uso universal simplificado de un lenguaje compartido como el "inglés internacional" (ibídem: 6). Esta concepción de la traducción se apoya, por un lado, en la afirmación de Bauman de que "la posibilidad del universalismo reside precisamente en esta capacidad común para alcanzar una comunicación efectiva sin poseer de antemano significados e interpretaciones comunes" (citado en Balibar 2006: 5). Por otro lado, Balibar parte de la visión benjaminiana de la traducción, que insiste en que la función de esta no es la de transmitir un contenido. Para Walter Benjamin, la traducción no desempeña una función de intermediario, sino que establece ante todo una cierta relación con lo ajeno. Este segundo paso fundamental para articular una política de la traducción consiste, por lo tanto, en afirmar que lo que importa de la traducción no es la información o los significados que transmite sino cómo los transmite y la relación que al hacerlo establece con lo foráneo. Este es el punto de partida de todos aquellos que proponen una política de la traducción contra la limitada definición dominante de la traducción; entre los contemporáneos, autores como Gayatri Spivak (2000), Antoine Berman (2003), y Lawrence Venuti (2008), a quienes nos vamos a referir más adelante. Y si a primera vista una definición que cuestiona la traducción como transmisión de contenidos de un idioma a otro nos puede parecer extraña, ello es debido a la estrecha definición de traducción a la que estamos acostumbrados, que la considera como un acto derivativo, como una mera reproducción de algo cuyo valor reside más allá de la traducción 
misma (de ahí que parezca que siempre hay algo que se pierde irremediablemente en la traducción). Definición que la trivializa y que la despolitiza.

3. Esta concepción alternativa y política de la traducción apunta a un tercer paso que es necesario subrayar: el hecho de que el etnocentrismo es una tendencia o resistencia central en todo acto de traducción. Este aspecto de la traducción no ha sido suficientemente reconocido en la literatura sociológica reciente sobre el cosmopolitismo, que tiende a presuponer una noción esencialmente idealista de la traducción (Bielsa 2014). Tanto Beck como Delanty asumen la posibilidad de trascender el etnocentrismo a través de la traducción. Para Beck, la traducción es "la facultad de verse a uno mismo desde la perspectiva del culturalmente distinto..." (2005: 126), mientras que para Delanty la traducción proporciona "la posibilidad de incorporar la perspectiva del Otro en la cultura propia" (2009: 13). Estas concepciones presuponen no solo la voluntad de una apertura genuina a la alteridad, sino también una relativa facilidad para comprender e incorporar la perspectiva del otro en la propia cultura, minimizando el grado de dificultad o de resistencia que puede encontrarse a la hora de embarcarse en tal traducción. Sin embargo, según Lawrence Venuti, la traducción es un acto fundamentalmente etnocéntrico (1998: 10). La definición de traducción que este autor propone pone el énfasis en la violencia que implica todo acto de traducción: "La traducción es la sustitución forzosa de las diferencias lingüísticas y culturales del texto extranjero por un texto que sea inteligible para el lector del lenguaje traductor." (2008: 14). Destacamos esta definición de la traducción como un acto de violencia etnocéntrica para problematizar la presuposición de Beck y de Delanty de que la traducción nos brinda la posibilidad de trascender el etnocentrismo y para subrayar que lo interesante de la traducción es más bien la pugna que se establece a través de ella con el etnocentrismo cultural. Quien mejor ha teorizado este importante aspecto de la traducción es Antoine Berman, que reflexiona sobre la paradoja existente entre la estructura etnocéntrica de toda cultura y lo que él describe como la finalidad ética del traducir, que es necesariamente la apertura, el diálogo, el mestizaje, el descentramiento (2003: 19). Para Berman, una mala traducción sería, no aquella en la que se manifiestan pérdidas de sentido del original, sino aquella que no deja ver al original en su extranjeridad, en su rareza no directamente asimilable a la cultura del receptor. Por eso Berman llama mala traducción a la traducción etnocéntrica, es decir, aquella que niega sistemáticamente la extranjeridad de la obra extranjera con el pretexto de la dificultad de su transmisión (2003: 20). Tanto la aproximación de Berman como la de Venuti a las dificultades y resistencias con las que se enfrenta la traducción nos remiten a la noción central de la inteligibilidad. Respetar al otro, hacer justicia a la diferencia del texto extranjero, significa resistirse en el mayor grado posible a la demanda etnocéntrica de inteligibilidad, a la violencia inherente de la traducción. Sin embargo, tal resistencia implica a su vez someter la lengua del traductor a la extrañeza de otra lengua y puede conducir a la producción de un texto que bordea lo ininteligible. La relevancia de estas cuestiones va más allá de una reflexión académica sobre la traducción y nos implica necesariamente a todos nosotros como consumidores de traducciones. ¿Estamos realmente dispuestos a enfrentarnos con traducciones opacas, difíciles, que ofrecen no un acceso pretendidamente transparente a la alteridad (un otro reconocible y aparentemente asimilable a nuestros patrones culturales) sino que hacen visible la dificultad de comprender al otro en su extrañeza? Y esto no solo en la literatura, donde podemos aceptar más fácilmente la autonomía del hecho literario y su distancia de una realidad cotidiana que damos por supuesta, sino también en las noticias traducidas, que son nuestra ventana al mundo, cuando ni siquiera somos capaces de percibir en ellas la mediación omnipresente de la traducción. Un ejemplo textual referente al todavía poco estudiado ámbito de la traducción de prensa permitirá hacer visible esta problemática. Roger Silverstone inicia su libro Media and Morality (2007) con una observación sobre una entrevista emitida por la BBC Radio 4 durante la guerra contra el terror en Afganistán. La entrevista es con un herrero afgano, que da su versión sobre la razón por la que las bombas caen sobre su pueblo: "Era porque - su voz traducida explicó - Al Qaeda había matado a muchos americanos y a sus asnos y había destruido algunos de sus castillos" (2007:1). Silverstone reflexiona sobre la extrañeza de la aparición del herrero en la radio británica, debida no solo a lo insólito de encontrarnos con el discurso de una persona corriente tan alejada de nosotros en las noticias, sino también a lo que dice y cómo lo dice, al hecho de que nos habla y, además, habla de nosotros, interpreta nuestra realidad y la suya para contarnos, a través de su voz, "una verdad traducida, una verdad cultural y una verdad que para él está llena de sentido" (2007: 1-2). Se trata, como comenta Silverstone, de la rara aparición de un extraño que irrumpe a través de los medios en nuestro hogar y que nos habla sobre nuestro infortunio además del suyo. Habría que añadir a esta reflexión que la rareza de esta presencia en la radio británica se debe además al hecho de que no se ha procurado esconder que se emite un discurso traducido. Esto contrasta con la forma dominante que adopta la traducción en los medios, que se caracteriza por privilegiar la fluidez y hacer que los otros hablen como lo haríamos nosotros, de forma que se oculta la extrañeza de su discurso y la misma traducción se convierte en un proceso invisible.

4. Es el etnocentrismo fundamental de la traducción, la tendencia reductora de toda cultura, lo que hace necesario formular una política de la traducción 
en un contexto cosmopolita. Una política de la traducción basada en la finalidad ética del traducir, que según Berman es la de establecer, a nivel de lo escrito, una cierta relación con el otro, fecundar lo propio mediante la reflexión sobre lo ajeno. Paul Ricoeur ha afirmado que el traductor puede encontrar la felicidad en lo que él ha denominado la "hospitalidad lingüística", apelando a un régimen de correspondencia sin adecuación que no borra la irreductibilidad del par de lo propio y lo extranjero (2005: 27-28). El cuarto paso para fundamentar una política de la traducción de apertura al otro consiste, por lo tanto, en invocar la noción derrideana de hospitalidad y plantear su relevancia en este contexto. Se trata de defender una hospitalidad incondicional y no un mero derecho de visita, como en la versión kantiana de la hospitalidad. Pues aunque Kant afirmaba de manera radical el derecho a la hospitalidad como un derecho de los individuos y no de los estados en un contexto cosmopolita, la hospitalidad kantiana quedaba atrapada en la paradoja de que garantizaba solo la entrada a un Estado pero no el derecho a residir permanentemente en él (Kant 2005: 157). Derrida apela a una noción de hospitalidad absoluta que:

"[...] rompe con la ley de la hospitalidad como derecho o deber, con el 'pacto' de hospitalidad. Para decirlo en otros términos, la hospitalidad absoluta exige que yo abra mi casa y que dé no solo al extranjero (provisto de un apellido, de un estatuto social de extranjero, etc.) sino al otro absoluto, desconocido, anónimo, y que le dé lugar, lo deje venir, lo deje llegar, y tener lugar en el lugar que ofrezco, sin pedirle ni reciprocidad (la entrada en un pacto) ni siquiera su nombre" (2000: 31).

Puede que la hospitalidad absoluta sea imposible, pero solo una hospitalidad lingüística entendida como hospitalidad incondicional que deje llegar la extrañeza de la lengua extranjera y no la oculte bajo una pretendida equivalencia o falsa familiaridad hará posible fecundar lo propio mediante la reflexión sobre lo ajeno, posibilitando así la incorporación de la perspectiva del otro a la cultura propia a la que Beck y Delanty se refieren. Como afirma Derrida, la hospitalidad absoluta rompe con la ley de la hospitalidad como derecho o deber. Más allá de la razón obvia de que traducir éticamente, es decir, hacer justicia a la diferencia del otro, no está contemplado en ningún régimen de derechos, se trataría de contemplar una política de la traducción basada en la hospitalidad lingüística como una responsabilidad y no como un derecho. Se trata de una responsabilidad que está más allá del derecho y que también cabe distinguir del deber (Aguilera 1999: 122-25), que no se puede normar y que, más bien, se basa y requiere un posicionamiento ético y político estratégico del traductor ante una situación concreta. Esta responsabilidad no solo se anticipa en muchos casos al derecho, o incluso se posiciona en determinadas instancias contra la norma para hacer posible la justicia, sino que se refiere a las circunstancias y condiciones en las que se puede establecer una comunicación genuina; lo que no puede abordarse desde un enfoque basado en los derechos, que aprueba cualquier tipo de comunicación mientras no se infrinjan los derechos de nadie.

Quisiéramos ilustrar este punto con dos ejemplos sobre el posicionamiento y la responsabilidad del traductor en un contexto marcado no solo por la diferencia cultural y lingüística sino también por una pronunciada desigualdad y asimetría. En ambos casos se considera cómo el traductor afronta los retos de la traducción desde una situación concreta que, como hemos afirmado, es el único lugar desde el que se puede articular una política de la traducción. El primero se refiere a las reflexiones de Gayatri Spivak sobre la traducción, en ensayos como "Translating into English" (2005) y, sobre todo, en el influyente ensayo titulado "The Politics of Translation" (2000). En ellos, la autora aborda la responsabilidad del traductor que traduce desde lenguas no europeas al inglés, responsabilidad que es mayor debido a ciertas complicaciones geopolíticas: el poder creciente del inglés como lingua franca global, la demanda de traducciones de literaturas no occidentales como un medio de acceso rápido a otras culturas y la inexistencia de una comunidad de políglotas en la sociedad receptora que pueda juzgar dichas traducciones. Para Spivak, solo desde una reflexión sobre la responsabilidad ética y política del traductor, que no simplemente transmite los contenidos de una literatura ajena sino que los reproduce asumiendo su opacidad desde lo que la autora denomina un sentido de la retoricidad del lenguaje, puede evitarse una construcción neocolonialista de la escena no occidental (2000: 399). Las asimetrías y desigualdades globales demandan una respuesta más inmediata por parte del traductor en el segundo de los ejemplos, que se refiere al contexto de la interpretación legal. Pongamos por caso al intérprete que claramente percibe en el acento del sujeto que está traduciendo que es de origen marroquí y no palestino de Ramallah como afirma ser, pero que decide no revelárselo a la policía para no perjudicarle. Como afirma Moira Inghilleri en su excelente libro Interpreting Justice, los principios de neutralidad o imparcialidad que recogen los códigos profesionales de los intérpretes no significan el abandono de las responsabilidades personales y sociales de su rol (2012: 51). En casos como el que nos hemos referido, el deber profesional del intérprete, que lo consigna al mero rol de mediador desde una pretendida neutralidad o imparcialidad, no le permitiría responder a los abusos de poder o injusticias de las que puede ser testigo, o incluso le conduciría a convertirse en cómplice de ellas. Así como la justicia está más allá de la ley, una política de la traducción basada en la hospitalidad lingüística está más allá de las obligaciones deontológicas del traductor, y nos obliga a pensar de otra forma. 
5. La política de la traducción constituye un aspecto importante y necesario de cualquier planteamiento sobre la posibilidad de un cosmopolitismo no eurocéntrico. La cuestión del eurocentrismo se ha planteado no solo como consecuencia de las críticas poscoloniales al cosmopolitismo occidental (Mignolo 2000; Mendieta 2009; Van der Veer 2002), sino también debido a la insatisfacción de algunos autores como Chris Rumford con la centralidad que se le atribuye a Europa en un proyecto cosmopolita o, en sus palabras, "con el deseo de instalar el cosmopolitismo como la 'gran idea' de Europa", que él percibe de manera más evidente en la obra de Habermas (2007: 3). Contribuciones recientes a este debate también han subrayado la relevancia de los cosmopolitismos no occidentales, como por ejemplo el cosmopolitismo poscolonial de Fanon (Go 2012). La traducción aparece en este contexto como una instancia crucial que permite una aproximación a las relaciones existentes entre tradiciones culturales distintas, tanto si se subraya la interconexión entre espacios, historias y tradiciones (Go 2012; Bhambra 2014) como si, desde un enfoque alternativo, se cuestiona la idea de la modernidad como una condición que simplemente se expande de occidente al resto del mundo y se reconoce la existencia e interacción entre diferentes formas de modernidad o modernidades múltiples (Eisenstadt 2000; Wagner 2011 y 2012) en la formulación de un concepto de modernidad cosmopolita (Beck y Grande 2010). Sin embargo, hasta ahora la literatura sociológica no ha explorado la relevancia de una política de la traducción y ha ignorado en gran parte la importancia central de las interconexiones lingüísticas en todo proyecto cosmopolita. Existe una notable excepción: un reciente artículo de Gerard Delanty donde se plantea la necesidad de traducir entre variedades distintas de cosmopolitismo como un aspecto clave de la construcción de un cosmopolitismo crítico no eurocéntrico (2014). La concepción de Delanty sobre la traducción cultural se apoya implícitamente en una política de la traducción basada en la hospitalidad lingüística. Lo que aquí defendemos es no solo la importancia de advertir el papel crucial de la traducción para mediar entre variedades distintas de cosmopolitismo, sino también la necesidad de explicitar que solo ciertas formas de traducción permiten esa posibilidad. La traducción puede usarse y se ha usado en proyectos etnocéntricos y eurocéntricos para abolir la diferencia de los otros y para presentarlos como falsamente familiares. Una política de la traducción basada en la hospitalidad lingüística que asume la responsabilidad de hacer justicia al otro, incluso cuando ello suponga cuestionar ciertas estructuras etnocéntricas que a menudo se dan por sentado, debe enfrentarse a múltiples impedimentos políticos, económicos y culturales derivados de la presión existente para la producción de traducciones rápidas, fluidas y transparentes que puedan ser inmediatamente con- sumidas por los públicos sin cuestionar los valores establecidos. Solo si somos conscientes de las dificultades a las que estas traducciones alternativas deben enfrentarse, así como del importante papel que pueden jugar en una dirección cosmopolítica, podrá contribuir a la construcción de un cosmopolitismo no eurocéntrico, particularmente a través de la traducción de formas significativas de cosmopolitismo no europeo que han sido marginalizadas. Esta es una forma de traducción muy relevante que invierte los flujos dominantes de la traducción global, que tienen lugar predominantemente de occidente hacia el resto del mundo y que puede convertirse en una importante fuente para el crecimiento y la renovación de proyectos genuinamente abiertos a otras formas de la imaginación cosmopolita.

6. La política de la traducción ofrece también una alternativa a la política de la identidad o del reconocimiento (Taylor 1994), que desde la década de 1970 ha sido un aspecto clave de la fundamentación de las políticas multiculturalistas en las democracias occidentales. Y es que una comprensión política de la traducción como la que defendemos aquí nos conduce a cuestionar aspectos fundamentales de lo que entendemos por identidad; hace explotar la misma noción de identidad. Desde esta perspectiva, la clave para la convivencia en sociedades heterogéneas no está en el reconocimiento de la identidad y de la diferencia cultural, sino en las prácticas de traducción cultural donde la apertura al otro conduce a la autocrítica y al cambio, a la percepción de los propios límites, nunca a reforzar una supuesta identidad originaria que emana de antiguos presupuestos sobre lo que son las culturas y los individuos. Así, Rada Ivekovic mantiene que:

"La idea de 'traducir entre culturas' como un gesto abierto relacional y recíproco de libertad que cuestiona al 'traductor' y al mismo 'original' puede oponerse a la arrogante idea comunitaria [...] algo limitante de un 'diálogo entre culturas' [...], que a menudo se propone desde un enfoque multiculturalista benévolo" (2006: 6).

En esta reflexión, Ivekovic comparte varios de los puntos que hemos elaborado en este artículo, empezando por una concepción política de la traducción que afirma que esta transforma de manera relevante tanto al texto original como a quien traduce. La idea de la transformación, de la incorporación de la perspectiva del otro en la cultura propia, está diametralmente opuesta a lo que hay detrás de una noción de identidad, de esta noción de una comunidad con fronteras definidas que presupone la idea de un diálogo entre culturas, que en realidad sirve para ocultar las asimetrías y diferencias existentes entre ellas. Como señala Ivekovic, la identidad esencializa y naturaliza la cultura. Mientras que la fuente principal de la identidad es el proceso de construcción de la otredad, la traducción apunta a un proceso inverso, el del intercambio radical entre formas diferentes de 
ser o existir, el del cuestionamiento de lo propio a la luz de lo ajeno que está en la base de una noción cosmopolita de apertura genuina al otro.

Pero esta defensa de una política de la traducción en contra de una noción de identidad no se remite solo a principios normativos y a cuestiones filosóficas, sino que además posee un aspecto eminentemente sociológico y empírico en el sentido que defiende Beck en su libro La mirada cosmopolita (2005). Vivimos en una realidad que, en cierto sentido, se ha cosmopolitizado. La mirada cosmopolita nos ayuda a percibir esa realidad cosmopolita ya existente, la realidad de la pertenencia múltiple o la hibridez cultural, de las vidas traducidas y de las familias globales, una realidad que escapa y que ya no puede ser comprendida por concepciones tradicionales de la identidad, que asumen una correlación natural entre la identidad de las personas y la pertenencia a un lugar. Si nos centramos, por ejemplo, en las familias globales, concepto con el que Beck y Beck-Gernsheim analizan un caso creciente y particularmente relevante a través del cual las contradicciones generadas por la globalización se manifiestan en la vida cotidiana e íntima de las familias (2012), vemos que en ellas no hay una noción de identidad posible que las defina, sino una continua lucha con la contradicción y la diferencia que las caracteriza, una traducción que es por definición siempre provisional y por lo tanto inacabada e infinita entre modos distintos de existir. Las familias globales cuestionan nuestras presuposiciones más familiares sobre lo que son las familias; son, como los extraños, ambivalentes figuras de la no identidad. De manera similar, una política de la traducción en clave cosmopolita hace aparecer la extrañeza en el seno de lo que nos es más familiar, de nuestro idioma materno. $Y$ solo cuando desaparece la identidad, lo indudable, la inmediatez no cuestionada de las circunstancias que nos rodean, estamos en condiciones de pensarnos y relacionarnos abiertamente con los otros en un mundo que se nos ha vuelto extraño.

7. La identidad en la no identidad permite romper con el supuesto de una bipolaridad entre una identidad como reiteración de algo positivo (sangre, suelo, lengua, etnia, cultura) o una fragmentación o descomposición en lo que carece de identidad. Pero para esa tarea de una identidad en lo no idéntico a nivel cosmopolita podría ser clave la hospitalidad lingüística, en la atención a un lenguaje que nos constituye y que ha de ir abriéndose a todo lo que aparece en nosotros y fuera de nosotros, en las formas más extrañas, sean discursivas o no, vengan de la vigilia o del sueño, de los otros lejanos o de lo más cercano y familiar, también puesto a distancia crítica. Aquí la noción de hospitalidad de Derrida tiene la enorme ventaja de hacer presente lo que excede al sujeto y ha de ser confrontado con él mismo, con otros, en cuanto al menos desde Levinas o desde Mead se hace presente que somos algo derivado de nuestra relación con el otro. Nada seríamos si no hubiéramos sido acogidos durante mucho tiempo por un otro (la madre) que, sin condiciones, se ha abierto a nuestra fragilidad, condición de todo lo humano, condición absoluta de su propia fortaleza y resistencia, de su adultez. Las paradojas son múltiples: aparece un otro que se interioriza como uno, surge una fragilidad que da pie a una mayor resistencia por la disponibilidad a hacerse con lo nuevo de un contexto cambiante en cada situación, en la historia misma. Vista desde la perspectiva antropológica de la constitución humana (Aguilera 1993) o de la función de una inteligencia que moviliza pulsiones, movimientos y sensaciones abiertos a lo otro, la noción de hospitalidad derridiana puede dar cuenta de la necesidad de incorporar lo extraño, pero pide demasiado pues invoca una no condicionalidad que ni siquiera queda restringida por la legalidad. Por eso aparece como verosímil una idea más realista, la de una tolerancia que, habiendo pasado por la noción de democracia, lleva a Habermas a establecerla como centro de lo social (1999). Hay que ser tolerante con los otros, en una sociedad o en el espacio cosmopolita, pero siempre dentro de la posibilidad de un entendimiento que pasa por un diálogo como núcleo de la democracia generalizada. Desde luego, siguiendo al mismo Habermas, no se puede olvidar el papel de los subsistemas sociales como un extraño marco que limita las interacciones o que puede colonizarlas, allí donde precisamente Derrida hace hueco para la noción de inconsciente. Si la idea de tolerancia igualitaria como condición para el diálogo permitiría establecer unas relaciones sociales que pudieran incorporar la interacción entre diversas culturas o formas de vida, sin embargo, sigue existiendo en esa noción de tolerancia habermasiana algo que la idea de hospitalidad derridiana hace valer en favor de una socialidad plenamente humana: la dificultad del entendimiento. Lo que invoca Derrida mediante espectros y fantasmas, al pensar una situación internacional, más allá del mero ámbito de una interacción lingüística, Habermas lo desplaza hacia los susbsistemas sociales que operarían con medios deslingüistizados, por encima de la interacción comunicativa propia del mundo de la vida. Pero ante la idea de tolerancia, que exigiría una nivelación igualitaria en una versión moderna, la idea de hospitalidad da cabida a la necesidad de admitir al otro incluso cuando no puede dialogar o simplemente no quiere hacerlo, cuando no hay simetría o igualdad. Tal hospitalidad recuerda la acogida del neonato en un claustro social o familiar, que puede tener lugar incluso con deficiencias notables. Esta perspectiva antropológica permite ir más allá de la elaboración kantiana de la hospitalidad antigua. Aceptar lo no inteligible del otro es la clave, lo incalculable del otro, lo no racional del otro, acogerlo como ser no reducible a su entendimiento o reconocimiento. No solo reconocerlo, ni comunicarse 
con él, sino darle acogida, cuidarlo, dejarle ser como ser humano, se le entienda o no. Desde este punto de vista, la idea de reconocimiento de Honneth no mejora la perspectiva habermasiana. La hospitalidad lingüística no es una mera generalización del cara a cara levinasiano como Habermas o Honneth pueden creer, en cuanto la entienden como sobregeneralización de un cuidado individual (Habermas 2006: 283). Ambos parecen preferir una perspectiva jurídica como clave. Una crítica de la sobregeneralización del reconocimiento (Aguilera 2015) es previa a una defensa de una hospitalidad que no es meramente jurídica ni llega a ser existencial.

Creemos que un concepto de hospitalidad lingüística mejoraría la idea de hospitalidad derridiana, dando parte de razón a lo que la tolerancia habermasiana invoca, al desplazarla en su despliegue, puesto que le quitaría el inquietante factor, el aterrador principio que niega la idea de tolerancia y le da su fuerza: abrirse a un absoluto que podría ser mortífero. Si en la hospitalidad incondicionada que admite al otro y le da cobijo sin preguntarle ni su nombre, ni sus intenciones, ni siquiera si es un delincuente o un terrorista, existe el peligro de que el mundo que da hospitalidad sea descompuesto, destruido, cabría pensar en una antesala de tal hospitalidad y su carga de absoluto, no una tolerancia, ni siquiera aquella que ya se ha despedido de las viejas jerarquías predemocráticas, la de las terribles guerras de religiones. Una hospitalidad lingüística daría cabida al otro en su lenguaje, en lo no inteligible de su lenguaje, como traducción que no se cierra, que no busca la inmediata utilidad. Le daría acogida a lo extraño para que al menos en el ámbito de nuestro lenguaje y de lo que abre el lenguaje en nuestra inteligencia y en nuestra afectividad, en nuestros sentidos y movimientos, en todas las inervaciones que ha implantado la socialización humana, se fuera depositando. Una extrañeza que de modo no absoluto podría crecer en nosotros hasta hacer posible realmente una acogida del otro, de su mundo e intenciones, sin que se tuviera que poner en peligro lo que somos de manera incondicional, como si el otro fuera algo sagrado, cuando lo es tan poco como nosotros mismos. Se trata de una hospitalidad lingüística como antesala de la hospitalidad real o social, que es clave para la interacción entre culturas y formas de vida en un contexto cosmopolita. Con lo cual se mostraría no solo la importancia de la traducción hospitalaria frente a la instrumental o incluso tolerante, sino que también se daría un primer paso para formular posibilidades políticas que se puedan concretar en espacios de normatividad no eurocéntrica entre culturas diversas. Es una forma de dar razones a la perspectiva de Derrida, que defiende una hospitalidad absoluta aunque poco verosímil -y que él mismo afloja mediante la diferencia entre justicia y derecho, entre ley general y leyes-, y a la de Habermas, que aboga por un diálogo en el espacio público ya cosmopolita que pudiera hacer frente a la dinámica sistémica puesta en juego por la globalización. En la comunidad política habermasiana, que redefine la identidad y el trato con los extraños a nivel global, no puede olvidarse que se trata de poner límites a una racionalización sistémica que ha llevado a una "colonización del mundo de la vida", de los diversos mundos de la vida, tan dura como las colonizaciones externas, las ejercidas fuera de Occidente. Para Habermas es necesario traducir lo sistémico en términos sociales para poder darle el papel de un marco en la sociedad moderna, pese a que la tensión entre lo político y lo económico, además del papel sistémico de la cultura (derecho, ciencia, arte, etc), no queda suficientemente articulado en sus últimas propuestas cosmopolitas. Mientras que, para Derrida, una política de la amistad o una internacional de la amistad debería conjurar los peligros del capitalismo feroz, del neoliberalismo depredador. La hospitalidad lingüística, que sería previa a cualquier posibilidad de diálogo o de interacción democrática, a nivel local o mundial, mantiene una relación con lo extraño sin entrega absoluta a su forma de vida o intenciones, como si la nuestra nada fuera o mereciera perecer o ponerse temerariamente en peligro. Sin amistad o afinidad alguna previa, sin exigencia de que lo ajeno sea susceptible de ser interpretado en clave de actividad comunicativa o luche por su reconocimiento, sin una indeterminación que evite el cálculo para no impedir la llegada del acontecimiento, pone lo extraño entre las dos exigencias, la habermasiana y la derridiana, como comunicabilidad y apertura, como tolerancia y hospitalidad. Lo extraño no es solo otras culturas que podrían interrelacionarse, al modo de comunidades religiosas para las que la tolerancia fue decisiva para evitar una destrucción mutua, como sugiere Habermas (2006: 255 y ss.), es también individuos singulares, que pueden o no incluirse en diversas comunidades políticas, y no menos importante: lo extraño es un conjunto de dinámicas sistémicas que dibujan ante la historia perspectivas inquietantes como la de una economía globalizada, o una política mundial llena de complejidades, o una cultura moderna autonomizada -donde la separación entre expertos y legos la aleja de la vida social en cuando comprensión o sentido que pudiera sustituir el papel de las viejas y nuevas imágenes del mundo-. Lo extraño está en los otros y en lo sistémico social, pero también "en nosotros", en lo que constituyéndonos se muestra no disponible, cual instrumento o método. Lo que une todo eso está en el lenguaje, en un lenguaje capaz de abrirse a lo calculable y a lo incomunicable, desde la posición de lo comunicable y de lo articulable o calculable. Habermas con Derrida. La traducción hospitalaria coloca todo eso en el lenguaje, en un esfuerzo lingüístico donde madura una larga experiencia reflexiva, tanto como el arte o el conocimiento teórico, en cuanto apuntan hacia la justicia de manera moderna, faliblemente, socialmente. 
8. Una política de la traducción hospitalaria se basa en una insistencia en el lenguaje en su materialidad, más allá de cualquier reducción de lo lingüístico a un juego de ideas que se transmite de un emisor a un receptor, del reduccionismo del lenguaje a la significación o a la discursividad, a la mera comunicación. Queda muy cerca de los procesos artísticos que son capaces de llevar esa hospitalidad a otros medios de expresión, pero siempre en derredor de los sentidos, de los movimientos, de lo pulsional, de una inteligencia humana capaz de establecer los medios y los fines para todo lo que sea deseos humanos, en toda su variedad y multiplicidad. Tal concepción del lenguaje se sitúa frente al idealismo lingüístico que pone énfasis en la significación o la discursividad, creyendo que los medios significantes solo son instrumentos de información o comunicación, lo que permite menospreciar no solo el aspecto estético del lenguaje, sino también lenguas y culturas aparentemente desligadas de ciertas líneas de desarrollo pretendidamente progresista. También se coloca frente a un cosmopolitismo idealista, que minimiza o no se toma en serio las dificultades reales que existen a la hora de adoptar la perspectiva del otro en la propia cultura, ignorando las resistencias culturales que emergen cuando uno se embarca en una traducción que no simplifica, que trata de dar hospitalidad a lo traducido. Es la idea de una identidad que no se constituye por su cerrarse a lo extraño no concebible, no inteligible, olvidándose de lo que hizo posible la constitución misma de esa identidad en cuanto socialización, enculturación o simple protección de una necesaria y propia vulnerabilidad, condición antropológica de las potencialidades humanas. La infancia es uno de los modelos clave para entender algo no inteligible ya para el adulto, como vio Benjamin al referirse a los niños como representantes del paraíso. ¿Cómo entrar en el lenguaje, en un mundo socializado sin atender prodigiosamente a lo extraño sin resistencia alguna que no derive de la propia experiencia que se va articulando? El neonato como un extraño que debe hacer de lo extraño mismo su mundo, para convertirse en miembro de un mundo social, para dejar de ser extraño. Sin embargo, no termina ese proceso que conduce a la adultez con un resultado que reduciría lo vivo humano a mera discursividad, inteligibilidad o reconocimiento, quedan muchos restos que el lenguaje arrastra, como permiten mostrar el psicoanálisis o la vieja cura de la palabra, la confesión cristiana o la atención psicológica en traumas o catástrofes. La aparente centralidad del entendimiento, sin que pueda negarse su necesaria primacía en condiciones de autoconservación, esconde la alienación en el lenguaje, una unilateralidad de lo racional. El ser humano concebido como un parto prematuro ha de encontrar un claustro social para terminar de desarrollarse, lleno de deficiencias en comparación con otros animales cercanos, incluso en lo que parecería lo más elemental para una antro- pología filosófica clásica (sentidos, movimientos, impulsos). Ese ser recibe su identidad de lo no idéntico que lo constituye, que estuvo antes de ser él mismo y que sigue estando ante él, pero de tal manera que no es reducible a la mera consciencia de ese individuo ni a la de la serie de seres humanos que lo han cuidado, lo que presupone a nivel individual y social una infraestructura de los procesos racionales que viene marcada por lo extraño, por lo no idéntico, por sensaciones, movimientos, pulsiones. Una concepción del lenguaje que atiende a su infraestructura sensomotriz y pulsional no solo permite conectar mejor con lo que no es idéntico a la significación lingüística, sino también con complejos procesos sociales que se sedimentan como lenguaje, que pueden ser dirigidos desde el lenguaje, especialmente cuando no se ve sin raíces. $Y$ es el arte en especial lo que en una modernidad secularizada recuerda esa infraestructura (también un pensamiento radical que no se deja conformar con las especializaciones como tabúes), una y otra vez en sus diversas conformaciones materiales: sonido, visualidad, movimientos, espacialidad, etc. Aquí simplemente sugerimos que hay una perspectiva que va más allá de la negatividad estética como clave para pensar el arte (Aguilera 2002), lo que podría situar mejor el papel del arte moderno como crítica radical de la razón, de la eficiencia, del progreso, de todo lo consagrado como familiar, beneficioso, útil, bueno; pero también daría espacio para encontrarse realmente con el otro, con lo que en su lenguaje se ha hecho para nosotros tratable.

Al situar en el centro una hospitalidad lingüística que anticipa y podría hacer accesible la hospitalidad real, se recoge de modo antropológico lo que el mismo lenguaje en el individuo y en lo social opera como discursividad, pero también como vitalidad social e individual, desde lo imaginario sociohistórico a unos sentidos y movimientos que rebasan tanto lo discursivo como lo meramente biológico. Los haría accesibles, conectables con ese trasfondo de nuestro propio lenguaje. En la identidad que permite entrever una hospitalidad lingüística, se podría evitar la identidad que se autofagocita, que se autoinmuniza, que se canceriza en los procesos de cierre, de repetición que se pretende eterna, pero que sigue siendo tan efímera y frágil como la otra, pero menos flexible y muchas veces menos resistente y difícilmente capaz de sobrevivencia. Lo que a nivel filogenético distingue a la inteligencia de lo instintivo no es mucho menos que esa flexibilidad, que es imposible sustentar desde la conservación del núcleo dogmático de un origen y de una esencialidad a la que sirve como un ídolo la vieja identidad identitaria. No hay tradición que perdure sin que sea renovada por lo extraño. La hospitalidad lingüística permite esa innovación sin despedirse ciegamente de lo que merece la pena ser conservado. Apoyada en una noción de lenguaje que incorpora la complejidad de la experiencia humana, la hospitalidad lingüísti- 
ca sería el núcleo de una política de la traducción abierta a lo extraño, ni cerrada ni absolutamente abierta. Una política de la traducción centrada en la hospitalidad lingüística dibuja en la situación cosmopolita una frontera porosa allí donde la hospitalidad derridiana invoca lo mesiánico, sin otro gesto que el de la negación, ya sin frontera alguna, sin mesianismo, y donde la tolerancia habermasiana demandaría una igualdad con exigencias aduaneras de tipo jurídico. En la evolución del pensamiento de estos importantes filósofos se mueve una tensión que creemos identificar en nuestra propuesta. A Derrida le ha hecho dejar un mínimo de Estado nación en el contexto internacional, como resto de una exigencia jurídica tras la noción de una justicia más allá del derecho, y a Habermas le ha llevado a insistir en una constitución cosmopolita con escasas fronteras, en una constelación postnacional. No seguiremos las implicaciones jurídicas y políticas aquí, pero creemos que el lenguaje es la mejor frontera para pensar la relación entre extraños. En su mínima distancia a la hospitalidad real esta política de la traducción podría dar forma social al acogimiento de la extrañeza, darle una consistencia no meramente negativa, la conformación en el lenguaje, en ese material de nuestra vigilia y del sueño, de anhelos colectivos, que ha modificado nuestra carne, que la remueve, que la envía más lejos que el espíritu concebido como mera idealidad, más allá de la cultura como mero juego simbólico.

\section{Agradecimientos}

La investigación para el presente artículo ha recibido financiación del Ministerio de Economía y Competitividad, referencias RYC-2010-06105, CSO201123097. Se han presentado versiones anteriores del trabajo en la Universidad de Coimbra, en la Universidad de Salerno, en la Universidad Católica Portuguesa y en la Universidad Autónoma de Barcelona. Los autores agradecen los comentarios recibidos por parte de asistentes a dichos actos.

\section{RefERENCIAS BibLIOGRÁficAs}

Aguilera, A. 1993. Hombre y cultura. Madrid: Trotta.

Aguilera, A. 1999. "Responsabilidad negativa". Pp. 115-140 en El reparto de la acción. Ensayos en torno a la responsabilidad, editado por M. Cruz y R. R. Aramayo. Madrid: Editorial Trotta.

Aguilera, A. 2002. "Atravesando la soberanía y el compromiso en arte". La Ortiga 33-35: 99-165.

Aguilera, A. 2015. "Insuficiencias del reconocimiento para una apertura cosmopolita al otro". Papers. Revista de Sociologia 100: 325-344. http://dx.doi.org/10.5565/rev/ papers. 2113

Archibugi, D. 2008. The Global Commonwealth of Citizens. Princeton y Oxford: Princeton University Press.

Balibar, É. 2010. "At the Borders of Citizenship: A Democracy in Translation?". European Journal of Social Theory 13: 315-322. http://dx.doi.org/10.1177/1368431010371751

Balibar, É. 2006. "Strangers as Enemies : Further Reflections on the Aporias of Transnational Citizenship". Globalization Working Papers. Université de Paris-X Nanterre and University of California, Irvine, (06/4).

Beck, U. 2005. La mirada cosmopolita o la guerra es la paz. Barcelona: Paidós.

Beck, U. \& E. Grande. 2010. Varieties of Second Modernity: The Cosmopolitan Turn in Social and Political Theory and Research. The British Journal of Sociology 61: 409-443. http://dx.doi.org/10.1111/j.1468-4446.2010.01320.x

Beck, U. y E. Beck-Gernsheim. 2012. Amor a distancia. Barcelona: Paidós.

Benhabib, S. 2002. The Claims of Culture. Princeton y Oxford: Princeton University Press.

Benhabib, S. 2004. The Rights of Others. Cambridge: Cambridge University Press.

Benhabib, S. 2011. Dignity in Adversity. Cambridge: Polity.

Berman, A. 2003. La prueba de lo ajeno. Las Palmas de Gran Canaria: Universidad de Las Palmas de Gran Canaria.
Bhambra, G. 2014. Connected Sociologies. Londres: Bloomsbury.

Bielsa, E. 2014. "Cosmopolitanism as Translation". Cultural Sociology 8: 392-406. http://dx.doi. org/10.1177/1749975514546235

Delanty, G. 2006. "The Cosmopolitan Imagination: Critical Cosmopolitanism and Social Theory". The British Journal of Sociology 51: 25-47. http://dx.doi.org/10.1111/ j.1468-4446.2006.00092.x

Delanty, G. 2009. The Cosmopolitan Imagination. Cambridge: Cambridge University Press.

Delanty, G. 2014. "Not All Is Lost in Translation: World Varieties of Cosmopolitanism". Cultural Sociology 8: 374391. http://dx.doi.org/10.1177/1749975514532261

Derrida, J. and A. Dufourmantelle. 2000. La hospitalidad. Buenos Aires: Ediciones de la Flor.

Eisenstadt, S. N. 2000. "Multiple Modernities". Daedalus 129: 1-29.

Go, J. 2012. "For a postcolonial sociology". Theory and Society 42: 25-55. http://dx.doi.org/10.1007/s11186-012-9184-6

Habermas, J. 1999. La inclusión del otro. Barcelona: Paidós.

Habermas, J. 2006. Entre naturalismo y religión. Barcelona: Paidós.

Inghilleri, M. 2012. Interpreting Justice. London and New York: Routledge.

Ivekovic, R. 2005. "Transborder Translating". Eurozine, http:// www.eurozine.com/transborder-translating/

Kant, I. 2005. Ensayos sobre la paz, el progreso y el ideal cosmopolita. Madrid: Cátedra.

Mendieta, E. 2009. "From imperial to dialogical cosmopolitanism". Ethics \& Global Politics 2: 241-258. http://dx.doi. org/10.3402/egp.v2i3.2044

Mignolo, W. 2000. "The Many Faces of Cosmo-polis: Border Thinking and Critical Cosmopolitanism". Public Culture 12: 721-748. http://dx.doi.org/10.1215/0899236312-3-721 
Ricoeur, P. 2005. Sobre la traducción. Buenos Aires: Paidós.

Robertson, R. 1992. Globalization. Social Theory and Global Culture. London: Sage.

Rumford, C. 2008. Cosmopolitan Spaces. London y New York: Routledge.

Santos, B. de S. 2005. "The Future of the World Social Forum: The work of translation". Development 48: 15-22. http:// dx.doi.org/10.1057/palgrave.development.1100131

Santos, B. de S. 2010. Descolonizar el saber, reinventar el poder. Montevideo: Trilce. http://dx.doi.org/10.1111/ dech.12026

Silverstone, R. 2007. Media and Morality. Cambridge: Polity Press.

Snell-Hornby, M. 2000. "Communicating in the Global Village: On Language, Translation and Cultural Identity". Pp. 11-28 Translation in the Global Village, edited by C. Schäffner. Clevedon: Multilingual Matters.

Spivak, G. 2000. The Politics of Translation. Pp. 397-416 en The Translation Studies Reader, edited by L. Venuti. London y New York: Routledge.
Spivak, G. 2005. "Translating into English". Pp. 93-110 in Nation, Language, and the Ethics of Translation, edited by S. Bermann y M. Wood. Princeton y Oxford: Princeton University Press. http://dx.doi. org/10.1515/9781400826681.93

Taylor, C. 1994. "The Politics of Recognition". Pp. 25-73 in Multiculturalism. Examining the Politics of Recognition, edited by A. Gutmann. Princeton: Princeton University Press.

Van der Veer, P. 2002. "Colonial Cosmopolitanism". Pp. 165179 en Conceiving Cosmopolitanism, edited by S. Vertovec \& R. Cohen. Oxford: Oxford University Press.

Venuti, L. 1998. The Scandals of Translation. London y New York: Routledge.

Venuti, L. 2008. The Translator's Invisibility: A History of Translation. London: Routledge.

Wagner, P. 2011. "From Interpretation to Civilization - and Back: Analyzing the Trajectories of Non-European Modernities". European Journal of Social Theory 14: 89106. http://dx.doi.org/10.1177/1368431010394511

Wagner, P. 2012. Modernity. Cambridge: Polity.

ESPERANZA BIELSA es profesora en el Departamento de Sociología de la Universitat Autònoma de Barcelona. Es autora de Ios libros Cosmopolitanism and Translation: Investigations into the Experience of the Foreign (Routledge, 2016), The Latin American Urban Crónica. Between Literature and Mass Culture (Lexington Books, 2006); coautora, junto a Susan Bassnett, de Translation in Global News (Routledge, 2009) y coeditora, con Christopher Hughes, de Globalization, Political Violence and Translation (Palgrave Macmillan, 2009).

ANTONIO AGUILERA es profesor Titular del Departamento de Historia de la Filosofía, Estética y Filosofía de la Cultura de la Universitat de Barcelona. Ha publicado entre otras cosas: Hombre y cultura (Trotta, 1996), e introducciones a los libros de Adorno Actualidad de la filosofía (Paidós, 1991) y de Gehlen Antropología filosófica (Paidós, 1993). Ha publicado artículos sobre Benjamin y Adorno en las revistas La ortiga, Convivium y Accent. Ha sido investigador en la Universidad de Frankfurt. 